\title{
Evaluating the Independent Intellectual Property base on Multiple Goals Decision-Making Method Model for Mechanical and Electrical Enterprises in Jilin Province
}

\author{
Jing Kang 1 Na Wang 1,2 Fuxia Wei 1 \\ 1Changchun University of Science and Technology \\ 2Department of business, Jilin University
}

\begin{abstract}
This article introduced Multiple Goals Decision- Making Method applying in the analysis of intellectual property of Jilin Province. First it was established evaluation index system of intellectual property, made the appropriate assignment to the influencing goals of the intellectual property by using expert evaluation then evaluated the current situation of intellectual property in Jilin Province through Multiple Goals Decision- Making Method .
\end{abstract}

Keywords : intellectual property index system evaluation model Multiple Goals Decision-Making Method

\section{Introduction}

Intellectual property was intangible property right, which involved intellectual laborers who taking apart in the creation of intelligence and the right which according to law of intellectual fruits. As different country had different legal provisions, the concept of intellectual property rights of different county varied, the author prefer the definition: intellectual property meant special rights for all the people in the activity of commercial operation after their completion of creative intellectual fruits in the fields of science, technology, culture, arts and industrial or commercial areas. Evaluation of intellectual property was an important link for fastening transformation of scientific 
and technological achievements meanwhile directly affected economic interests and enthusiasm of two property rights transactions sides.As evaluation of intellectual property started relatively late in China and no mature evaluation system. The evaluate methods which adopted at present were costing method, income method, market method or different combination of these there methods. These evaluate methods had fatal weakness that evaluation of intellectual property was restricted with personal level, the knowledge structure, a sense of responsibility and other human factors. Multiple Goals Decision-Making Method was a new method to evaluate intellectual property and its results was fair and resonable.

\section{General principle of Multiple Goals Decision-Making Method}

Multiple Goals Decision-Making Method considered multiple goals in fuzzy environment to making decision.

Given twe limited sets:

$$
U=\left\{X_{1}, X_{2}, \cdots X n\right\}
$$$$
V=\left\{y_{1}, y_{2}, \cdots y_{n}\right\}
$$

$\mathrm{U}$ represents multiple goal set; V repesents differernt evaluation of decision , evalutation set. Ganerally, different goals in goal set have differernt effec on evalutation, A represent weight distribution of goals:

$$
A=\left(a_{1}, a_{2}, \cdots a_{n}\right) \in \mathrm{F}(\mathrm{U})
$$

$\mathrm{a}_{\mathrm{i}}$ represent weight of i-goal which satisfies:

$$
\sum_{i=1}^{n} a_{i}=1
$$

In addtion, m-evaluations are not absolutely affirmation or negation, $\mathrm{B}$ is fuzzy set of V :

$$
\mathrm{B}=\left(b_{1}, b_{2}, \cdots b m\right) \in \mathrm{F}(\mathrm{V}) \quad \mathrm{b}_{\mathrm{j}}
$$

represent the weight of j-evalution in total

Given fuzzy relation $\mathrm{R}=\left({ }^{r_{i j}}\right) \mathrm{n} \times \mathrm{m}$, then we can get fuzzy transformation $T_{R}, \mathrm{~A}$ mathematical model of comprehensive fuzzy evaluation:

a.goal set $\mathrm{U}=\left\{X_{1} X_{2} \ldots X_{n}\right\}$

b.evalution set $\mathrm{V}=\left\{y_{1}, y_{2} \ldots, y_{n}\right\}$

c.fuzzy transformation:

$$
\begin{gathered}
T_{R}: \mathrm{F}(\mathrm{U}) \rightarrow \mathrm{F}(\mathrm{V}) \\
A \mid \rightarrow A \bullet R
\end{gathered}
$$

In which $\mathrm{R}$ represents fuzzy related matrix, $\mathrm{R}=\left(r_{i j}\right) \mathrm{n} \times \mathrm{m}$, then $\mathrm{U}, \mathrm{V}, \mathrm{R}$ constuct mathematical model of comprehensive fuzzy evaluation. Given $\mathrm{A}=\left(a_{1}, a_{2}, \cdots a_{n}\right) \in \mathrm{F}(\mathrm{U})$,we can get a comprehensive evalutaion:

$$
\mathrm{B}=\left(b_{1}, b_{2}, \cdots b_{m}\right) \in \mathrm{F}(\mathrm{V}),
$$

That is: $\left(b_{1}, b_{2}, \cdots b_{m}\right)=\left(a_{1}, a_{2}, \cdots a_{n}\right)$

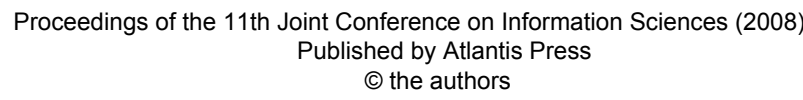




$$
\times\left(\begin{array}{cccc}
r_{11} & r_{12} & \cdots & r_{1 m} \\
r_{21} & r_{22} & \cdots & r_{2 m} \\
\cdots & \cdots & \cdots & r_{n m}
\end{array}\right)
$$

bj is fitting degree of m-evaluation and parameters needed for comprehensive evaluation.

\section{Multiple Goals Decision- Making Method of mechanical and electrical enterprises}

In order to use Multiple Goals DecisionMaking Method apply to mechanical and electrical enterprises in Jilin province we should construct model on the base of Multiple Goals Decision-Making Method. First, uesed general principles of evalutaion intellectural property formulate index system, and then setted goal set, evalutaion set and goal weight form the piont of experts, drawed evaluation of experts. Through rearrangement and calculation of the evaluation from experts we could get evaluation matrix.

The evaluation process as shown:

\section{a. determine evaluation set (U)}

$$
\mathrm{U}=\left(X_{1}, X_{2}, \cdots X_{n}\right)
$$

We should consider all the goals which affect the price of intellectual property. There were different content of different intellectual property, the goals which influeced price were different, so we should determine different evaluation set for different intellectual property. Table 1 gave us index system in the evaluation process of intellectual property in Jilin.

\section{b. evaluation set and its score $(W)$}

$$
\mathrm{V}=\left(y_{1}, y_{2}, \cdots y_{m}\right)
$$

Evaluation set was the rank of total evaluation conclusions made by relative expers. Evaluation set could not be set too many, nor too little, too many was difficult for expert to master standards and less was not conducive to distinguish between the good and the bad. As the ultimate evaluate subject was $U$, its evaluation set was:

$\mathrm{V}=$ (higher, high, average, poor poorer)

Determined its realtive scores:

$$
\mathrm{W}=(90,80,65,50,30)
$$

\section{c.detemined singel goal evaluation matrix}

Evaluation matrix could be drawed by expert interview and Delphi method. Firs, made certain of experts, and divided them into n groups, gave experts questionnaire about each goal. The evaluation of goals, high or low, made a conclusion proportion of experts by average- $\mathrm{r}_{\mathrm{ij}}$.For the other goals used the same method. For example, j-goals, solicit the views of 100 experts in which 60 experts belived that was reasonable, 20 experts belived that was lower and 20 experts belived that was higher, then the results of $\mathrm{j}$-goals were $\quad \mathrm{Rj}=\left(\begin{array}{lllll}0 & 0.2 & 0.6 & 0.2 & 0\end{array}\right)$. Comprehensive finishing solicit views of all goals we could conclude

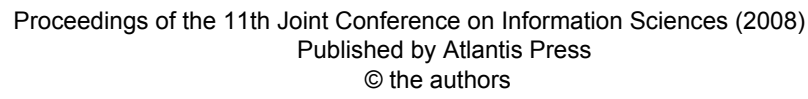


$\mathrm{R}=\left(r_{i j}\right)_{n \times m}$.

\section{d. determined weight set(A)

$$
\mathrm{A}=\left(a_{1}, a_{2}, \cdots a_{n}\right)
$$

Weight set represented the impotant degree of each goal.

\section{e. comprehensive fuzzy evaluated}

$$
\mathrm{B}=\mathrm{A} \times \mathrm{R}=\left(b_{1}, b_{2}, \cdots b_{m}\right)
$$

Fuzzy operated weigh set A multiplied by evaluation matrix $\mathrm{R}$, we could get comprehensive evaluation matrix B.

\section{f.calculated scores}

Comprehensive evaluation matrix B multiplied by scores matrix, we could get comprehensive situation scores of intellectrual property $\mathrm{U}$ :

$$
U=W \cdot B^{T}
$$

Through the above operation, we could get comprehensive situation scores of intellectrual property in Jilin.

4 Comprehensive situation fuzzy analysis index system for mechanical and electrical enterprises intellectrual property in Jilin

In order to enhance the objectivity and practicality of intellectual property evaluation, on the base of scentific principle, advanced and applicability principle, cost-effective and reliable principle, security and confidentiality principle, supply and demand principle, highest and best principle, expectations principle, relevant principles and environmental change principle, this paper established comprehensive situation fuzzy analysis index system for mechanical and electrical enterprises intellectrual property in Jilin, abide by the following evaluation of principles: principle of combing mathematical analysis and mechanism analysis, principle of combing state evaluation and trend evaluation and principle of combing ability evaluation and capacity-building measures designed.

Comprehensive situation of mechanical and electrical enterprises intellectrual property in Jilin should be evaluated from the piont of independent innovation ability, independent intellectual property evaluation and management performance of independent intellectual property, namely $U=\left\{\boldsymbol{u}_{1}, \boldsymbol{u}_{2}, \boldsymbol{u}_{3}\right\}=\{$ independent innovation ability, independent intellectual property evaluation, management performance of independent intellectual property\};first grade indexes independent innovation ability had four scond grade indexes: technological innovation resources ability, technological innovation operation ability, technological innovation environmental resistance and technological innovation new output value, namely $u_{1}=$ $\left\{\quad u_{11}, u_{12}, u_{13}, u_{14}\right\}=\{$ technological innovation resources ability,

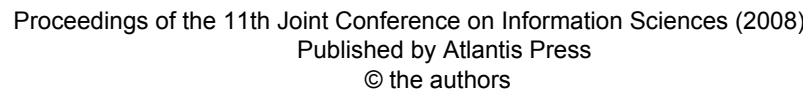


technological innovation operation ability, technological innovation environmental resistance, technological innovation new output value\};first grade indexes independent intellectual property evaluation had three scond grade indexes: input-output ratio, technical degree and economic benefit, namely $u_{2}=$ $\left\{\boldsymbol{u}_{21}, \boldsymbol{u}_{22}, \boldsymbol{u}_{23}\right\}=\{$ input-output ratio, technical degree, economic benefit\}; first grade indexes management performance of independent intellectual property had five scond grade indexes: intellectual property strategy, information system of intellectual property, the development and operation of intellectual property, intellectual property protection and intellectual property management, namely $u_{3}=\left\{u_{31}, u_{32}, u_{33}, u_{34}, u_{35}\right\}$ $=\{$ intellectual property strategy, information system of intellectual property, the development and operation of intellectual property, intellectual property protection, intellectual property management , as the table1 shown:

Table1 comprehensive situation of mechanical and electrical enterprises intellectrual property in Jilin

\begin{tabular}{|c|c|c|c|c|}
\hline & $\begin{array}{l}\text { first } \\
\text { grade }\end{array}$ & weight & scond grad & weight \\
\hline \multirow[t]{7}{*}{$U$} & \multirow{4}{*}{$u_{1}$} & \multirow{4}{*}{0.4} & $u_{11}$ & 0.3 \\
\hline & & & $u_{12}$ & 0.2 \\
\hline & & & $u_{13}$ & 0.2 \\
\hline & & & $u_{14}$ & 0.3 \\
\hline & \multirow{3}{*}{$u_{2}$} & \multirow{3}{*}{0.4} & $u_{21}$ & 0.4 \\
\hline & & & $u_{22}$ & 0.4 \\
\hline & & & $u_{23}$ & 0.2 \\
\hline
\end{tabular}

\begin{tabular}{|c|c|c|c|}
\hline \multirow{4}{*}{$\boldsymbol{u}_{3}$} & \multirow{3}{*}{0.2} & $\boldsymbol{u}_{31}$ & 0.1 \\
\cline { 3 - 4 } & & $\boldsymbol{u}_{32}$ & 0.3 \\
\cline { 3 - 4 } & & $\boldsymbol{u}_{33}$ & 0.2 \\
\cline { 3 - 4 } & & $\boldsymbol{u}_{34}$ & 0.3 \\
\hline & & $\boldsymbol{u}_{35}$ & 0.1 \\
\hline
\end{tabular}

5 Comprehensive situation fuzzy analysis evaluation for mechanical and electrical enterprises intellectrual property in Jilin

We adopted the method of fuzzy analysis to evaluate mechanical and electrical enterprises independent intellectural property in Jilin.We had retained 10 groups of experts as our evaluation groups to evaluate echanical and electrical enterprises independent intellectural property in Jilin, evaluative steps as follow:

a.given goal set: $U=\left\{U_{1}, U_{2}, U_{3}\right\}$,

$\mathrm{U}_{\mathrm{i}}$ represent goals, $\mathrm{i}=1,2,3,4,5$;

$U_{1}=\left\{u_{11}, u_{12}, u_{13}, u_{14}\right\}$,

$U_{2}=\left\{u_{21}, u_{22}, u_{23}\right\}$,

$U_{3}=\left\{u_{31}, u_{32}, u_{33}, u_{34}, u_{35}\right\}$, as table1 shown。

b. evaluation set and its score: $\mathrm{V}=\left\{v_{1}, v_{2}, v_{3}, v_{4}, v_{5}\right\}, V_{j}$ represent evaluation resluts,j=1,2,..,5, as table 2 shown:

\begin{tabular}{|l|l|l|}
\hline Rank V & evaluation & scores $\mathrm{W}$ \\
\hline $\mathrm{V}_{1}$ & higher & 90 \\
\hline $\mathrm{V}_{2}$ & high & 80 \\
\hline $\mathrm{V}_{3}$ & average & 65 \\
\hline
\end{tabular}




\begin{tabular}{|l|l|l|}
\hline $\mathrm{V}_{4}$ & poor & 50 \\
\hline $\mathrm{V}_{5}$ & poorer & 30 \\
\hline
\end{tabular}

Table2 evaluation set and its score

c.detemined singel goal evaluation matrix $R_{i}=\left\{r_{i j}\right\}$

$$
\begin{aligned}
R_{1} & =\left(\begin{array}{lllll}
0.2 & 0.1 & 0.3 & 0.2 & 0.2 \\
0.3 & 0.1 & 0.1 & 0.3 & 0.2 \\
0.3 & 0.1 & 0.2 & 0.2 & 0.2 \\
0.1 & 0.2 & 0.2 & 0.2 & 0.3
\end{array}\right) \\
R_{2} & =\left(\begin{array}{lllll}
0.2 & 0.3 & 0.3 & 0.1 & 0.1 \\
0.3 & 0.1 & 0.2 & 0.3 & 0.1 \\
0.1 & 0.2 & 0.3 & 0.2 & 0.2
\end{array}\right) \\
R_{3} & =\left(\begin{array}{lllll}
0.2 & 0.1 & 0.3 & 0.2 & 0.2 \\
0.3 & 0.1 & 0.1 & 0.3 & 0.2 \\
0.3 & 0.1 & 0.2 & 0.2 & 0.2 \\
0.3 & 0.2 & 0.2 & 0.2 & 0.1 \\
0.1 & 0.3 & 0.1 & 0.3 & 0.2
\end{array}\right)
\end{aligned}
$$

d. determined weight set(A)

$$
\begin{aligned}
& A_{1}=U_{1}=\left(\begin{array}{llll}
0.3, & 0.2, & 0.2, & 0.3
\end{array}\right) \\
& A_{2}=U_{2}=\left(\begin{array}{lll}
0.4, & 0.4, & 0.2
\end{array}\right) \\
& A_{3}=U_{3}=(0.1,0.3,0.2,0.3,0.1)
\end{aligned}
$$

comprehensive fuzzy evaluation and its index

$B_{1}=A_{1} \times R_{1}=(0.21,0.13,0.21,0.22$, 0.23 )

$$
B_{2}=A_{2} \times R_{2}=(0.22,0.2,0.26,0.2 \text {, }
$$

0.12 )

$$
B_{3}=A_{3} \times R_{3}=(0.27,0.15,0.17,
$$

$0.24,0.17$ )

$$
\begin{gathered}
R=\left(\begin{array}{c}
B_{1} \\
B_{2} \\
B_{3}
\end{array}\right) \quad \begin{array}{l}
\text { improve innovation ability } \\
\text { and electrical enterprises } \\
\text { enhance the competitive } \\
\text { mechanical and electrical }
\end{array} \\
\text { Proceedings of the 11th Joint Conference on Information Sciences (2008) } \\
\text { Published by Atlantis Press } \\
\text { @ the authors } \\
6
\end{gathered}
$$

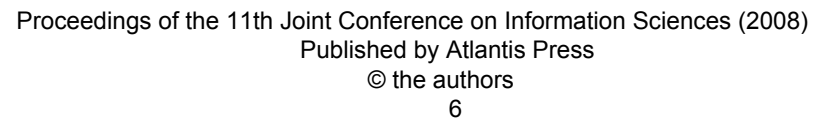

As $U=\left\{u_{1}, u_{2}, u_{3}\right\}$ singal goal evaluation matrix,its weight distribution was:

$A=(0.4,0.4,0.2)$

e.second comprehensive fuzzy evaluation

$$
\mathrm{B}=A \times \mathrm{R}=\left(\begin{array}{lll}
0.4 & 0.4 & 0.2
\end{array}\right) \times
$$

$\left(\begin{array}{ccccc}0.21 & 0.13 & 0.21 & 0.22 & 0.23 \\ 0.22 & 0.2 & 0.26 & 0.2 & 0.12 \\ 0.27 & 0.15 & 0.17 & 0.24 & 0.17\end{array}\right)$
$=(0.226,0.162,0.222,0.216,0.174)$ f. evaluate mechanical and electrical enterprises independent intellectural property in Jilin U,

$$
\begin{gathered}
U=W \cdot B^{T}=[90,80,65,50,30] \bullet \\
{[0.226,0.162,0.222,0.216,0.174]^{T}}
\end{gathered}
$$

$=63.75$

From the above calculation results known, comprehensive situation of mechanical and electrical enterprises intellectrual property in Jilin belongs to $\mathrm{V}_{3}$, we could conclude comprehensive situation of mechanical and electrical enterprises intellectrual property in Jilin was general. In order to enforce the siuation of mechanical and electrical enterprises intellectrual property in Jilin, improve innovation ability of mechanical and electrical enterprises in Jilin and enhance the competitive ability of mechanical and electrical enterprises in 
Jilin, we should take measures from the aspects of independent innovation ability, independent intellectual property evaluation and management performance of independent intellectual property.

\section{Reference}

[1]Cheng Shuyan, Wu Mingzan. The application of Multiple Goals Decision- Making Method in evaluation of enterprise rescouces [M].Operation reseach and management, 2002, (6): 101-105

[2]Yu Shulian. intangible assets appraisal[M]. Beijing: Publishing House of University of International Business and Economics,2003

[3]Han Zheng zhong, Fang Ninsheng. Fuzzy mathematical application [M]. Nanjing: Publishing House of southeast university,1993

[4]Changyu, Liu Xiandong. The application of multiple goals and fuzzy evaluation in enterprise technology innovation[J]. the Science and Technology Progress,2002(9):25-27

[5]Jiang Qiu, Wang Nin. Intellectual property evaluation based on Goals Decision- Making Method [D].thechnology and innovation management, 2005, (6):73-76 